\title{
Análisis e interpretación de la ejecución del Tratado de Libre Comercio entre México y Panamá
}

\section{Analysis and interpretation of the execution of the Free Trade Agreement between Mexico and Panama}

Bertha Angélica Lastra Mora ${ }^{1}$, Dr. Germán Martínez Prats², Dra. Francisca Silva Hernández ${ }^{3}$.

${ }^{1}$ Universidad Juárez Autónoma de Tabasco, México Berthalasm13@gmail.com

ORCID: https://orcid.org/0000-0001-6197-4771

Universidad Juárez Autónoma de Tabasco, México germanmtzprats@hotmail.com

ORCID: https://orcid.org/0000-0001-6371-448X

${ }^{3}$ Dra. Francisca Silva Hernández

Universidad Juárez Autónoma de Tabasco, México

fany987@hotmail.com

ORCID: https://orcid.org/0000-0003-3533-0002

Dor https://doi.org/10.46589/rdiasf.vi35.369

Recibido 22 de febrero 2021.

Aceptado 15 de marzo 2021

Publicado 30 de junio de 2021

\section{Resumen}

El Tratado de Libre Comercio con Panamá entro en vigor en el 2015, después de al menos 15 años de negociaciones, el tratado incluye el acceso a los mercados, reglas y procedimientos aduaneros relacionados con el origen, medidas sanitarias y fitosanitarias, obstáculos técnicos al comercio, defensa comercial, inversión, comercio electrónico, comercio transfronterizo de servicios, entrada temporal, servicios financieros, telecomunicaciones, propiedad intelectual, solución de controversias y asuntos institucionales. Panamá es un país que puede beneficiar a México como centro logístico para la distribución de productos al mercado global, al igual que es un puente a América del Sur ya que está en una ubicación estratégica, y México como centro para la manufactura.

Palabras clave: Balanza comercial, comercio internacional, exportación, tratados comerciales. 


\begin{abstract}
The Free Trade Agreement with Panama entered into force in 2015, after at least 15 years of negotiations, the agreement includes access to markets, customs rules and procedures related to origin, sanitary and phytosanitary measures, technical barriers to trade. , trade defense, investment, e-commerce, cross-border trade in services, temporary entry, financial services, telecommunications, intellectual property, dispute resolution, and institutional matters. Panama is a country that can benefit Mexico as a logistics center for the distribution of products to the global market, as well as being a bridge to South America since it is in a strategic location, and Mexico as a center for manufacturing.
\end{abstract}

Key words: Trade balance, international trade, export, trade agreements.

\title{
Introducción
}

Los tratados de Libre Comercio son acuerdos que firman dos o más países para construir una relación comercial que permita intercambiar libremente sus productos y servicios. Con estos acuerdos se busca aumentar el comercio y la inversión de ambas partes. La importancia de estos tratados se encuentra en crear una estructura comercial duradera que resulte beneficiosa para el desarrollo de los países que participen.

En los últimos años se han percatado de que los países que más han logrado el desarrollo son aquellos que se han incorporado exitosamente al comercio internacional, ampliando de esta manera el tamaño del mercado para sus sectores empresariales. La necesidad de que cada país debe especializarse en aquellos productos o servicios, cuya elaboración y producción son más eficientes, por lo que el papel de la productividad en el desarrollo de las economías nacionales.

La teoría de la ventaja comparativa (Huerta, 2009) nos dice que cada país en cuestión se especializará en los productos en lo que sea más eficiente y, a su vez, importará el resto de los productos en los que son más ineficaces en términos de producción.

Por eso es importante que las naciones creen lazos comerciales entre ellas para que lo que una nación no pueda producir por sí mismo lo comercien con otras y se realicen transacciones con el excedente de ciertos productos. 
Actualmente México cuenta con 12 Tratados de Libre Comercio con 46 países ,32 Acuerdos para la Promoción y Protección Recíproca de las Inversiones (APPRIs) con 33 países y 9 acuerdos en el marco de la Asociación Latinoamericana de Integración.

\section{Definición y Teorías del Comercio Internacional}

"El comercio internacional, se define como el conjunto de transacciones comerciales realizadas entre privados, residentes en distintos países. A diferencia del comercio interior, donde las transacciones comerciales se efectúan dentro de un espacio económico, monetario y jurídico relativamente homogéneo, las transacciones comerciales internacionales se realizan entre operadores comerciales privados situados en diferentes ordenamientos jurídicos y con acentuadas diferencias económicas y sociales" (Ginés \& Stampa, 2009: 24).

El Comercio Internacional es el intercambio de bienes y servicios que se realiza de forma transfronteriza. Los países no siempre pueden producir todo lo que necesitan dentro de su territorio, ya sea porque no tienen los medios tecnológicos o no cuentan con las condiciones (climáticas, sociales o económicas) necesarias para su elaboración. Es por esto que se realizan los intercambios de mercancías, ya que algunos otros países producen en excedente de lo que otro necesita o algunos otros se especializan en la producción de algún bien.

Cuadro 1. Teorías del Comercio Internacional.

\begin{tabular}{|c|l|}
\hline Autor & \multicolumn{1}{|c|}{ Teoría } \\
\hline Mercantilistas & $\begin{array}{l}\text { La idea básica de los mercantilistas era que la riqueza de la nación } \\
\text { se lograba acumulando metales preciosos como resultado de un } \\
\text { saldo positivo de la balanza comercial. Supusieron que en el ámbito } \\
\text { nacional debería ocurrir lo mismo que en el personal: los individuos } \\
\text { se hacían ricos atesorando dinero. } \\
\text { Siendo esta la concepción fundamental, algunos autores se } \\
\text { centraron en la defensa del comercio interior, proponiendo el } \\
\text { desarrollo de las estructuras productivas nacionales y la remoción } \\
\text { de las barreras que lo dificultaban. }\end{array}$ \\
\hline Adam Smith - & $\begin{array}{l}\text { Adam Smith en su Obra La Riqueza de las naciones (2015) } \\
\text { argumentó que un país posee ventaja absoluta sobre los demás en } \\
\text { Ventaja Absoluta producción de un bien cuando puede producir mayores } \\
\text { cantidades de este con los mismos recursos que los países vecinos. } \\
\text { Para Smith, cada país debería especializarse únicamente en la } \\
\text { producción de aquellas mercancías en las que gozara de } \\
\text { condiciones naturales que le predeterminaran una ventaja absoluta; } \\
\text { esta ventaja puede provenir de costos de producción bajos, } \\
\text { recursos naturales favorables o superioridad tecnológica. }\end{array}$ \\
\hline
\end{tabular}




\begin{tabular}{|c|c|}
\hline $\begin{array}{c}\text { David Ricardo - } \\
\text { Ventaja } \\
\text { Comparativa }\end{array}$ & $\begin{array}{l}\text { Según Ricardo (2009) los países exportarían aquellos bienes y } \\
\text { servicios en los que mostraban una mayor ventaja interna en los } \\
\text { costes de producción con relación a los bienes o servicios } \\
\text { producidos por otros sectores de la economía nacional, e } \\
\text { importarían aquellos otros bienes y servicios en los que su ventaja } \\
\text { interna de costes fuera menor, a pesar de que éstos últimos podían } \\
\text { mostrar unos costes de producción más bajos que los de sus socios } \\
\text { económicos (Ramíres et al, 2018) y comerciales. } \\
\text { Según el principio de la ventaja comparativa, los países pueden } \\
\text { especializarse en la producción de los bienes que puedan fabricar } \\
\text { a un costo relativamente menor, aun sin gozar de condiciones } \\
\text { absolutas ventajosas para su producción. }\end{array}$ \\
\hline $\begin{array}{l}\text { El modelo de } \\
\text { comercio de } \\
\text { heckscher-ohlin }\end{array}$ & $\begin{array}{l}\text { El teorema Heckscher-Ohlin (H-O) expone que una nación } \\
\text { exportará la mercancía cuya producción requiera el uso intensivo } \\
\text { del factor relativamente abundante y barato, e importará la } \\
\text { mercancía cuya producción requiera de uso intensivo del factor } \\
\text { relativamente escaso y caro, en otras palabras, la nación } \\
\text { relativamente rica en trabajo exporta la mercancía relativamente } \\
\text { intensiva en trabajo, e importa la mercancía relativamente intensiva } \\
\text { en capital (Ruíz, 2020). }\end{array}$ \\
\hline $\begin{array}{c}\text { Nueva teoría del } \\
\text { comercio } \\
\text { internacional }\end{array}$ & $\begin{array}{l}\text { La nueva teoría del comercio empezó a surgir en la década de los } \\
\text { setenta (González, 2011). Muchas industrias experimentaban } \\
\text { rendimientos crecientes de la especialización, debido a la presencia } \\
\text { de economías sustanciales de escala. Además, los teóricos del } \\
\text { nuevo comercio aseveran que, por la presencia de economías de } \\
\text { escala importantes, la demanda mundial únicamente apoyará a } \\
\text { unas cuantas empresas en varias industrias. Los teóricos del nuevo } \\
\text { comercio afirman que los países pueden exportar ciertos productos } \\
\text { simplemente porque cuentan con una empresa que entró por } \\
\text { primera vez en una industria que sólo puede sostener a unas } \\
\text { cuantas empresas. Gracias a que pueden obtener economías de } \\
\text { escala, los primeros en entrar en una industria pueden colocar un } \\
\text { candado en el mercado mundial que desaliente los intentos de una } \\
\text { penetración subsecuente. }\end{array}$ \\
\hline $\begin{array}{c}\text { Políticas } \\
\text { Comerciales }\end{array}$ & $\begin{array}{l}\text { Los gobiernos establecen diferentes políticas comerciales, las } \\
\text { cuales influyen en todas las acciones que toman las empresas del } \\
\text { país con el fin de afectar las cantidades y diversidad de productos } \\
\text { que se transan con otros países. } \\
\text { En la actualidad, los gobiernos no tienen autonomía para establecer } \\
\text { nuevas políticas comerciales, debido a que existen compromisos } \\
\text { adquiridos no solo en términos de acuerdos multilaterales como el } \\
\text { de la Organización Mundial de Comercio (OMC), sino también } \\
\text { acuerdos regionales (por ejemplo Mercosur, Unión Europea, etc.). }\end{array}$ \\
\hline
\end{tabular}

Fuente: Elaboración propia con datos de diversos autores. 


\section{El principio de la nación más favorecida y el nacimiento del GATT}

Los cimientos del sistema multilateral de comercio moderno se establecieron en los años inmediatamente posteriores a la Segunda Guerra Mundial, que fue un período favorable para el logro de progresos importantes en la liberalización y la cooperación en el comercio internacional. Los Estados Unidos habían salido de la guerra como la superpotencia económica indiscutida y tenían razones comerciales y de política internacional de mucho peso para impulsar el sistema internacional en la dirección del multilateralismo. Además, los vencedores en la guerra, especialmente Gran Bretaña y los Estados Unidos, tenían una coincidencia casi total con respecto a las causas del caos político y económico del período de entreguerras y querían construir un sistema económico internacional que hiciera imposible que volviera a imperar la inestabilidad financiera y la rivalidad de bloques comerciales que había desencadenado la guerra (Informe sobre el comercio mundial, 2012).

En la Conferencia de Bretton Woods celebrada en 1944 se decidió la creación de tres nuevas instituciones económicas internacionales que serían los pilares de un nuevo orden económico mundial: el Fondo Monetario Internacional (FMI), que mantendría la estabilidad del tipo de cambio, el Banco Internacional de Reconstrucción y Fomento, o Banco Mundial, que proporcionaría capital para las tareas de reconstrucción a los países asolados por la guerra, y la Organización Internacional del Comercio, que supervisaría la administración de un orden comercial multilateral abierto y no preferencial. El FMI y el Banco Mundial vieron la luz, pero no así la Organización Internacional del Comercio, principalmente por las preocupaciones del Congreso de los Estados Unidos sobre la pérdida de soberanía en favor del organismo comercial propuesto.

Los países retomaron el Acuerdo General sobre Aranceles Aduaneros y Comercio (GATT) provisional que se había negociado entre 23 "partes contratantes" en 1947 y que sería la base de un sistema multilateral de comercio en expansión hasta que fue absorbido por la OMC en 1995.

\section{Tratado de Libre Comercio}

Un tratado comercial o de comercio es un acuerdo que establecen dos o más países bajo el amparo del derecho internacional y con el objetivo de mejorar sus relaciones en términos económicos y de intercambio comercial.

Cuando son tratados de libre comercio (TLC) se establecen reglas para realizar el intercambio de productos y de servicios, eliminando los obstáculos (arancelarios, impuestos, etc.) en las importaciones y las exportaciones. 
Estos tratados comerciales ofrecen las siguientes ventajas:

- Acceso a mercados más amplios

- Competitividad y acceso a una mayor diversidad de productos y servicios

- Eliminación de condiciones y barreras comerciales

- Intercambio de tecnología

\subsection{Importancia de los Tratados}

Los Tratados de Libre Comercio forman parte de una estrategia comercial de largo plazo que busca consolidar mercados (Vallejo, 2011) para los productos peruanos con el fin de desarrollar una oferta exportable competitiva, que a su vez genere más y mejores empleos. La experiencia muestra que los países que más han logrado desarrollarse en los últimos años son aquellos que se han incorporado exitosamente al comercio internacional, ampliando de esta manera el tamaño del mercado para sus empresas. La necesidad de promover la integración comercial como mecanismo de ampliación de mercados es bastante clara en el caso del Perú, cuyos mercados locales, por su reducido tamaño, ofrecen escasas oportunidades de negocios y, por tanto, de creación de empleos.

\subsection{Incumplimiento de un acuerdo internacional}

En caso de que un país no cumpla con un acuerdo internacional, su socio iniciará consultas para conocer en detalle, los movimientos del incumplimiento.

En caso de que ese país esté enfrontando dificultades, pero desee cumplir el acuerdo, ambos pueden negociar una estrategia que permita su cumplimiento, que puede incluir tanto una prórroga o modificación del acuerdo original, como la celebración de un nuevo acuerdo.

Si ese país no desea más seguir formando parte del acuerdo, notificará entonces a su socio dicha decisión y el acuerdo será cancelado (denunciado).

Algunos acuerdos contienen reglas más elaboradas para resolver incumplimientos. Es el caso de los acuerdos entre miembros de la Organización Mundial del Comercio (OMC): si un país interpreta que fue perjudicado por otro, puede solicitar que la OMC juzgue el caso.

\subsection{Antecedentes de relaciones Comerciales de México}

El inicio de la Segunda Guerra Mundial abrió una ventana de oportunidad para el comercio y la industrialización de México. Durante los siete años de la guerra (1939 
-1945), los países europeos dejaron de exportar y los EE.UU. empezaron a concentrarse en la fabricación de productos militares. México, mientras tanto, aprovechó la situación para exportar productos manufacturados como textiles y uniformes, alimentos y bebidas (Leguizamon \& Yepes, 2014) y materias primas como el hierro. Durante la década de 1930, con la inauguración de la carretera Panamericana, el comercio exterior tuvo la alternativa de utilizar el transporte terrestre. Con el tiempo y con el desarrollo de otras carreteras, esta alternativa de transporte ganó relevancia, hasta que sobrepasó al ferrocarril en términos del volumen de comercio a finales del siglo XX. Veinte años después, durante la década de 1950, México entró en una fase de industrialización sobre la base del modelo (Martínez \& Pino, 2016) de sustitución de importaciones. Aumentó los aranceles, aislando la economía mexicana del resto del mundo.

El comercio exterior disminuyó en importancia en el Producto Interno Bruto (PIB) del país (Concha, 2002). Dicho modelo duró 25 años hasta mediados de la década de 1970, cuando grandes reservas petroleras fueron encontradas en el Golfo de México. "La decisión de la sustitución de importaciones fue cancelada debido a la petrolización de la economía", indica Riguzzi. Para 1982, el modelo de sustitución de importaciones seguía su curso y las exportaciones de petróleo crudo dominaban, aportando alrededor del 80\% del valor (Millán \& Camilo, 2015) de las exportaciones mexicanas. En ese momento, el gobierno mexicano decidió que era tiempo de diversificar sus exportaciones y se puso en marcha una política de apertura comercial y de liberalización de la inversión. En 1986, México se unió al Acuerdo General sobre Aranceles Aduaneros y Comercio (GATT), el cual evolucionó hacia lo que hoy conocemos como la Organización Mundial del Comercio (OMC).

Ocho años después, en 1994, el Tratado de Libre Comercio de América del Norte (TLCAN) entró en vigor entre México, los EE.UU. y Canadá, lo cual detonó las exportaciones e importaciones. Durante los años siguientes, México ha firmado una serie de tratados comerciales bilaterales y regionales, llegando a un total de 49 socios comerciales.

Según la Secretaria de Economía, actualmente, contamos con una red de 12 Tratados de Libre Comercio con 46 países, 32 Acuerdos para la Promoción y Protección Recíproca de las Inversiones (APPRIs) con 33 países y 9 acuerdos en el marco de la Asociación Latinoamericana de Integración.

México participa activamente en diversos foros multilaterales y regionales para impulsar un sistema multilateral de comercio sólido que dé mayor certeza al intercambio comercial y a los flujos de inversión extranjera directa.

Cuadro 2. Tratados Comerciales firmados por México 
Año 14 / Núm. 35 / Enero-junio 2021

Revista de Investigación Académica sin Frontera

ISSN 2007-8870

UNISON

"A suber de mis hijo
hara mi gandea"

\begin{tabular}{|c|c|c|c|c|}
\hline Tratado & $\begin{array}{l}\text { Entrada } \\
\text { en } \\
\text { Vigencia }\end{array}$ & $\begin{array}{c}\text { Países } \\
\text { Miembros }\end{array}$ & $\begin{array}{c}\text { Comentario } \\
\mathrm{s}\end{array}$ & Fuente \\
\hline $\begin{array}{l}\text { T-MEC } \\
\text { (Tratado entre } \\
\text { México, Estados } \\
\text { Unidos y Canadá) }\end{array}$ & $\begin{array}{l}2020^{\star} \\
\text { (Pendiente } \\
\text { ratificación } \\
\text { por } \\
\text { Canadá }^{\star *} \text { ) }\end{array}$ & $\begin{array}{l}\text { México } \\
\text { Canadá } \\
\text { USA }\end{array}$ & $\begin{array}{l}\text { Firmado en } \\
\text { Noviembre } \\
2018, \\
\text { Ratificado por } \\
\text { México en } \\
\text { Junio } 2019\end{array}$ & $\begin{array}{l}\text { Secretará de Economía. En } \\
\text { Línea. Disponible en } \\
\text { https://www.gob.mx/t-mec } \\
\text { Consultado el } 19 \text { de Abril de } \\
2020 .\end{array}$ \\
\hline $\begin{array}{l}\text { ACE } 55 \\
\text { (Acuerdo de } \\
\text { Complementación } \\
\text { Económica No. 55) }\end{array}$ & 1 Enero 2003 & $\begin{array}{l}\text { México } \\
\text { Argentina } \\
\text { Brasil } \\
\text { Uruguay } \\
\text { Paraguay }\end{array}$ & & $\begin{array}{l}\text { Diario Oficial de la Federación } \\
8 \text { Abril } 2011\end{array}$ \\
\hline Alianza del Pacífico & 29 Julio 2015 & $\begin{array}{l}\text { México } \\
\text { Chile } \\
\text { Colombia } \\
\text { Perú }\end{array}$ & $\begin{array}{l}49 \text { Estados } \\
\text { Observadores }\end{array}$ & $\begin{array}{l}\text { Cancillería de Colombia. En Líne } \\
\text { pisponible en } \\
\text { https://www.cancilleria.gov.co/int } \\
\text { hal/consensus/pacific-alliance } \\
\text { fonsultado el } 19 \text { Abril } 2020\end{array}$ \\
\hline $\begin{array}{l}\text { Tratado de Libre } \\
\text { Comercio entre } \\
\text { México y } \\
\text { Centroamérica }\end{array}$ & $\begin{array}{l}\text { 1 Septiembre } \\
2012\end{array}$ & $\begin{array}{l}\text { México } \\
\text { Costa Rica } \\
\text { Guatemala } \\
\text { El Salvador } \\
\text { Honduras } \\
\text { Nicaragua }\end{array}$ & & $\begin{array}{l}\text { Secretaría de Economía. En } \\
\text { Línea. Disponible en } \\
\text { http://www.economia- } \\
\text { snci.gob.mx/sicait/5.0/ } \\
\text { Consultado el } 20 \text { de Abril } \\
2020\end{array}$ \\
\hline $\begin{array}{l}\text { Tratado de } \\
\text { Asociación } \\
\text { Traspacífico (TPP) }\end{array}$ & $\begin{array}{l}30 \text { Diciembre } \\
2018\end{array}$ & $\begin{array}{l}\text { Australia } \\
\text { Brunei } \\
\text { Darussalam } \\
\text { Canadá } \\
\text { Chile } \\
\text { Estados } \\
\text { Unidos } \\
\text { Japón } \\
\text { Malasia } \\
\text { México } \\
\text { Nueva Zelanda } \\
\text { Perú } \\
\text { Singapur } \\
\text { Vietna }\end{array}$ & & $\begin{array}{l}\text { Secretaría de Economía. } \\
\text { Tratado Integral y Progresista } \\
\text { de Asociación Transpacífico. }\end{array}$ \\
\hline $\begin{array}{l}\text { TLCUEM } \\
\text { Tratado de Libe } \\
\text { Comercio entre } \\
\text { México y la Unión } \\
\text { Europea }\end{array}$ & 1 Julio 2000 & $\begin{array}{l}\text { México } \\
\text { Unión Europea }\end{array}$ & $\begin{array}{l}\text { Actualizado y } \\
\text { en proceso de } \\
\text { ratificación por } \\
\text { parte de UE } \\
\text { para entrar en } \\
\text { vigor en } 2020\end{array}$ & $\begin{array}{l}\text { Secretaría de Economía. } \\
\text { Tratado de Libre Comercio } \\
\text { México - Unión Europea } \\
\text { Modernizado. }\end{array}$ \\
\hline
\end{tabular}


Año 14 / Núm. 35 / Enero-junio 2021

Revista de Investigación Académica sin Frontera ISSN 2007-8870

\begin{tabular}{|l|l|l|l|l|}
\hline $\begin{array}{l}\text { Tratado de Libre } \\
\text { Comercio México - } \\
\text { Asociación Europea } \\
\text { Libre Comercio }\end{array}$ & 1 Julio 2001 & $\begin{array}{l}\text { México } \\
\text { Noruega } \\
\text { Islandia } \\
\text { Liechtenstein }\end{array}$ & $\begin{array}{l}\text { No confundir } \\
\text { AELC con UE. }\end{array}$ & $\begin{array}{l}\text { Diario Oficial de la } \\
\text { Federación. 29 de Junio 2001 }\end{array}$ \\
\hline $\begin{array}{l}\text { Tratado de Libre } \\
\text { Comercio México - } \\
\text { Panamá }\end{array}$ & 1 Julio 2015 & $\begin{array}{l}\text { México } \\
\text { Panamá }\end{array}$ & & \\
\hline $\begin{array}{l}\text { Tratado de Libre } \\
\text { Comercio México - } \\
\text { Colombia }\end{array}$ & $\begin{array}{l}2 \text { Agosto de } \\
2011\end{array}$ & $\begin{array}{l}\text { México } \\
\text { Colombia }\end{array}$ & & \\
\hline $\begin{array}{l}\text { Tratado de Libre } \\
\text { Comercio México - } \\
\text { Israel }\end{array}$ & $\begin{array}{l}1 \text { de Julio de } \\
2000\end{array}$ & $\begin{array}{l}\text { México } \\
\text { Israel }\end{array}$ & & $\begin{array}{l}\text { Secretará de Economía. En } \\
\text { Línea. } \\
\text { https://www.gob.mx/cms/uplo } \\
\text { ads/attachment/file/224507/2. } \\
\text { 4.8_Mx-Israel.pdf }\end{array}$ \\
\hline $\begin{array}{l}\text { Tratado de Libre } \\
\text { Comercio México - } \\
\text { Chile }\end{array}$ & $\begin{array}{l}1 \text { de Agosto } \\
\text { de 1999 }\end{array}$ & $\begin{array}{l}\text { México } \\
\text { Chile }\end{array}$ & $\begin{array}{l}\text { Secretará de Economía. En } \\
\text { Línea. } \\
\text { https:/www.gob.mx/cms/uplo } \\
\text { ads/attachment/file/224506/2. } \\
\text { 4.7_Mx-Chile.pdf }\end{array}$ \\
\hline
\end{tabular}

Fuente: Elaboración Propia con datos de la secretaria de Economía

\section{Antecedentes de México con Panamá}

México y Panamá establecieron relaciones diplomáticas el 1 de marzo de 1904, fecha en la que nuestro país reconoció a la República de Panamá (Organización de los Estados Americanos, 2020).

Durante la década de 1980, México y Panamá formaron parte del Grupo Contadora, el cual sentó las bases para los modelos de cooperación y diálogo existentes en la región; son miembros del Proyecto de Integración y Desarrollo de Mesoamérica, y del Mecanismo de Diálogo y Concertación de Tuxtla.

El 21 de agosto de 1995, se creó la Comisión Binacional México-Panamá, con el propósito de fomentar los contactos entre ambos países e impulsar la cooperación bilateral en diferentes campos: político, económico, comercial, financiero, así como fortalecer las coincidencias en los ámbitos regional e internacional. A la fecha se han realizado cinco reuniones de la Comisión Binacional: la primera en México en enero de 1996; la segunda en Panamá en julio de 2003; la tercera en la Ciudad de México del 11 al 12 de julio de 2005; la cuarta en febrero de 2014, en la Ciudad de México; y la quinta en la Ciudad de México en noviembre de 2015.

Durante la V Reunión de la Comisión Binacional México-Panamá, los temas abordados fueron: el fortalecimiento de la cooperación en materias académica, diplomática, y de seguridad; la firma de dos memorándums de entendimiento, uno en materia de cooperación en la lucha contra el combate a la delincuencia 
organizada transnacional, y otro en materia académico-diplomática; así como el fortalecimiento de las relaciones en temas de orden político, económico, comercial, turismo y cooperación técnica y científica.

De acuerdo con la Cancillería mexicana, la relación bilateral México-Panamá se ha fortalecido con las siguientes acciones:

- Apoyo a México para su ingreso como miembro observador del SICA (Sistema de la Integración Centroamericana).

- Ampliación de las facilidades migratorias para personas de negocios y turistas panameños. Inauguración de las instalaciones de la sede de la Cámara de Comercio México-Panamá, así como el establecimiento de una Oficina de la Red Interamericana de Comercio, ubicadas en el World Trade Center, ciudad de Panamá.

- Suscripción del Acuerdo Concerniente a la Exoneración del Pago de los Derechos por Servicios de Navegación Aérea a las Naves del Jefe de Estado o de Gobierno en Visita de Estado u Oficiales, así como de las Aeronaves utilizadas por los Integrantes de su Comitiva Oficial (mediante Canje de Notas de 1 de junio y 29 de septiembre de 2005, fecha de entrada en vigencia).

- Tratado de Extradición, firmado en Panamá, el 2 de noviembre de 2004.

- Firma del Acuerdo de Modificación del Convenio sobre Transporte Aéreo suscrito el 14 de febrero de 1996, celebrado mediante Canje de Notas del 11 de octubre de 2005.

- Suscripción del Acuerdo para la Promoción y Protección Recíproca de las Inversiones (APPRI), celebrado en México el 11 de octubre de 2005.

Para fortalecer las relaciones bilaterales, impulsar el comercio, diversificar las exportaciones y multiplicar las inversiones con otros países, México y Panamá firmaron un Tratado de Libre Comercio. Este acuerdo busca fortalecer el intercambio comercial de bienes y servicios; impulsar las inversiones recíprocas; y consolidar la posición de ambos países como plataformas logísticas de alcance global, sentando las bases para un corredor comercial en el continente americano.

El Tratado se negoció en cinco rondas, que concluyeron formalmente el 24 de marzo de 2014; fue suscrito el 3 de abril de 2014, en la Ciudad de Panamá y aprobado por el Senado mexicano el 12 de marzo de 2015. Entró en vigor el 1 de julio del mismo año.

Con este Tratado, México tendrá acceso inmediato y a corto plazo (5 años) al $72 \%$ del universo arancelario acordado de bienes, en productos como: cables de cobre y aluminio, acero, automóviles, autopartes, pinturas, cosméticos y perfumería, aguacate, frambuesas, sémola de trigo, chicles, tequila, mezcal y jugo de naranja. El resto del material arancelario acordado se desgravará paulatinamente. 
El Gobierno mexicano estima que el Tratado permitirá profundiz ar la integración económica entre México y la región Centroamericana-Caribe, fomentar la diversificación de las exportaciones mexicanas y brindar certidumbre jurídica a los flujos de inversión. Cabe mencionar que las economías de México y Panamá son complementarias, Panamá brinda servicios de excelencia mundial y México es una potencia manufacturera.

Para 2013 México fue el quinto socio comercial de Panamá en exportaciones y el vigésimo octavo en importaciones; a la inversa, Panamá es el vigésimo primer socio comercial de México en exportaciones y el octogésimo octavo en importaciones

Para 2015, el año en el que el tratado entro en vigor, el comercio entre México y Panamá fue de 921,640 millones de dólares, con un total de 1, 042,422 millones de dólares en exportaciones, e importaciones provenientes de Panamá por 120,782 millones de dólares.

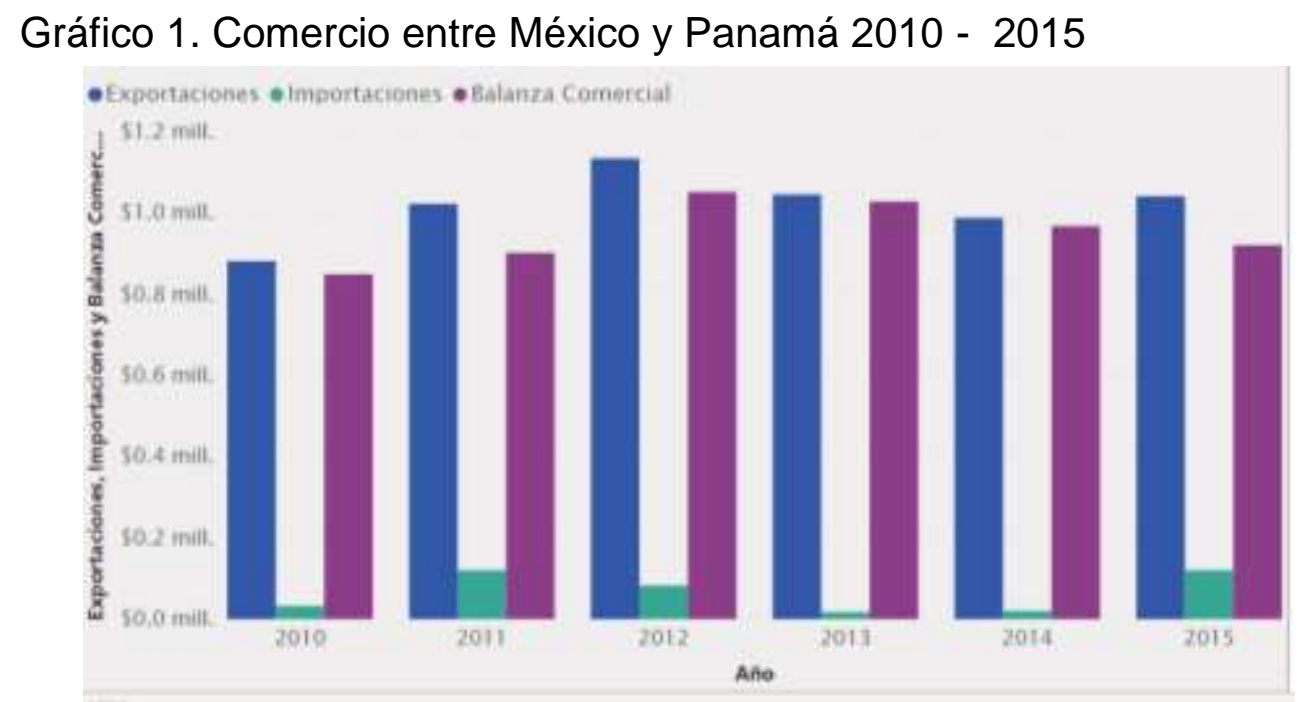

Fuente: Elaboración propia con datos de SAT, SE, BANXICO, INEGI. Balanza Comercial de Mercancías de México (1993 - 2020).

México y Panamá también tienen suscritos otros acuerdos relacionados con el ámbito comercial y de las inversiones:

- El 11 de octubre de 2005, México y Panamá suscribieron un Acuerdo de Promoción y Protección Recíproca de las Inversiones (APPRI), el cual entró en vigor el 14 de diciembre de 2006. 
- Los días 11 y 12 de noviembre de 2009, México y Panamá concluyeron la negociación de un Convenio en Materia de Doble Tributación, en el que se incluye una cláusula de intercambio de información tributaria, con lo cual nuestro país se comprometió a excluir a Panamá del listado de territorios con regímenes fiscales preferentes. El Convenio se suscribió en febrero de 2010. El 30 de abril de 2010, la Asamblea Nacional de Panamá aprobó el proyecto de ley sobre el Convenio entre México y Panamá para Evitar la Doble Imposición y Prevenir la Evasión Fiscal en Materia de Impuestos sobre la Renta. En el caso de México, la Cámara de Senadores del H. Congreso de la Unión lo aprobó el 19 de octubre de 2010 y entró en vigor el 30 de diciembre del mismo año.

- Por otra parte, Panamá solicitó y obtuvo, con el apoyo de México, la aprobación para su ingreso a la Asociación Latinoamericana de Integración (ALADI) en 2009. La adhesión de Panamá al Tratado de Montevideo de 1980 (TM 80) se formalizó el 2 de febrero de 2012, mediante el depósito del Instrumento de Adhesión y la suscripción de los protocolos de adhesión a los siete acuerdos regionales en los que participan todos los países miembros de la Asociación Latinoamericana de Integración (ALADI); en consecuencia, Panamá es miembro pleno de dicho organismo a partir del 3 de marzo de 2012.

\section{Marco normativo}

En la ley sobre la aprobación de tratados internacionales (Hernández, 2004) en materia económica, se plantea el marco jurídico dentro del cual los acuerdos internacionales deben realizarse, es destacable de dicha ley la naturaleza de sus objetivos los cuales son los siguientes

I. Contribuir a mejorar la calidad de vida y el bienestar de la población mexicana II. Propiciar el aprovechamiento de los recursos productivos del país

III. Promover el acceso de los productos mexicanos a los mercados internacionales IV. Contribuir la diversificación de mercados

V. Fomentar la integración de la economía mexicana con la internacional y contribuir a la elevación de la competitividad del país, y

VI. Promover la transparencia en las relaciones comerciales internacionales y el pleno respeto a los principios de política exterior de la fracción $\mathrm{X}$ del artículo 89 de la constitución política de los Estados Unidos Mexicanos.

Al analizar los objetivos se puede observar un interés no solo por recibir ganancias monetarias, sino también por desarrollar herramientas y capacidades para que la competitividad del país se vea beneficiada durante y después de la celebración de los acuerdos. 
También se observa un interés por la transparencia del actuar internacional de las finanzas y capitales que están en juego en los tratados, esto basado en un artículo constitucional.

\section{Conclusión}

Podemos observar en la gráfica las fluctuaciones en el cambio que ha tenido el Tratado de Libre comercio entre México y Panamá. En el año 2014 que es un año antes del tratado tenemos un decremento del 10\% con respecto al 2012 en la Balanza Comercial.

Pasado 3 años de la firma del tratado podemos ver que para la balanza comercial no ha traído beneficios significativos para nuestro país, debido a que solo creció un $0.3 \%$. Se esperaría que después entrar en vigor el tratado los flujos en la balanza comercial tuvieran un efecto positivo.

Las importaciones de Panamá a México después del tratado han tenido un crecimiento de $27.4 \%$, con esto podemos concluir que el país que ha logrado un beneficio con este tratado es Panamá, debido a que para México las exportaciones no logran tener un cambio significativo.

A pesar de que la balanza comercial se ha mantenido a favor de nuestro país, la divergencia entre exportaciones e importaciones ha sido menor desplazando el equilibrio de la balanza a favor de Panamá. Con excepción de 2018 que tuvo un crecimiento contra 2012.

A partir de los resultados encontrados en esta investigación puedo deducir que el tratado no ha traído consigo un cambio significativo en la dinámica comercial de estos países, debido a que no proporciona beneficios que impacten a ambos países esto lo podemos ver en la relación de cuanto influye las exportaciones e importaciones en el PIB de estos países, para 2018 este tratado represento para el PIB de México un $0.000095 \%$ y por parte de Panamá un $0.000163 \%$

\section{Bibliografía}

Concha Velásquez, José Roberto. (2002). ¿Cuándo los países aumentan sus exportaciones les va mejor? Revista Estudios Gerenciales, 18(84), 89-101.

Ginés Castellet, Núria y Stampa, Gonzalo. (2009). El arbitraje internacional. Cuestiones de actualidad. México: Bosch.

González Blanco, Raquel. (2011). Diferentes teorías del comercio internacional. Revista Tendencias y nuevos desarrollos de la teoría económica ICE, 858, 103-117. 
Hernández Villalobos, Larys Leiba. (2004). Los tratados internacionales como base de la diplomacia mundial. Revista de Derecho, 22, 65-95.

Huerta Quintanilla, Rogelio. (2009). Ventajas comparativas y política industrial en una economía abierta. Revista Investigación económica, LXVIII (269), 113141.

Informe sobre el comercio mundial 2011. (2012). Antecedentes históricos y tendencias actuales. 51.

Leguizamon Sierra, Gabriela Inés \& Yepes Gonzalez, Nelson V. (2014). Estudio Descriptivo Mediante Análisis Multicriterio de la Cadena Agroalimentaria de La Panela. Revista Publicaciones e Investigación, 8, 161-183.

Martínez, John y J. Pino, Francisco. (2016). Definición de un Modelo de Calidad de Servicios Soportado por Tecnologías de la Información (TI). Revista Publicaciones e Investigación, 10, 49-67.

Millán Cifuentes, Andrés \& Felipe González, Claudio Camilo. (2015). Marco de Referencia para la Gestión de TI Centrada en la Creación de Valor Compartido. Revista Publicaciones e Investigación, 9, 163-176.

Organización de los Estados Americanos. (2020). Sistema de información sobre comercio exterior, Tratado de Libre Comercio México-Panamá.

Oscar Anchorena, Sergio. (2009). Comercio internacional: ventajas comparativas, desventajas distributivas. Revista Entre líneas de la política económica, 23, 37.

Ramírez del Rio, Délany; Soto Mejía, José Adalberto \& Rentería Ramos, Rafael Ricardo. (2018). Diseño de un modelo bajo el enfoque de dinámica de sistemas para estudiar comportamiento de la dinámica socioeconómica basada en la atención de primer infancia, infancia y adolescencia. Revista Investigación Operacional, 39(2), 220-233.

Ruíz Nápoles, Pablo. (2020). El teorema Heckscher-Ohlin y la economía mexicana. Una visión crítica de la economía neoliberal. Revista el trimestre económico, LXXXVII(345), 99-131.

SAT, SE, BANXICO, INEGI. (2020). Balanza Comercial de Mercancías de México (1993-2020).

Smith, Adam. (2015). La riqueza de las naciones. México: Alianza.

Vallejo Zamudio, Luis E. (2011). El Tratado de Libre Comercio (TLC) y sus implicaciones. Revista Apuntes del CENES, 30(52), 7-8. 
Cómo citar este artículo

Martínez Prats, G., Lastra Mora, B. ., \& Silva Hernández, F. . (2021). Análisis e interpretación de la ejecución del Tratado de Libre Comercio entre México y Panamá. Revista De Investigación Académica Sin Frontera: División De Ciencias Económicas Y Sociales, (35), 15. https://doi.org/10.46589/rdiasf.vi35.369

https://revistainvestigacionacademicasinfrontera.unison.mx/index.php/RDIASF/article/view/3 $\underline{69}$
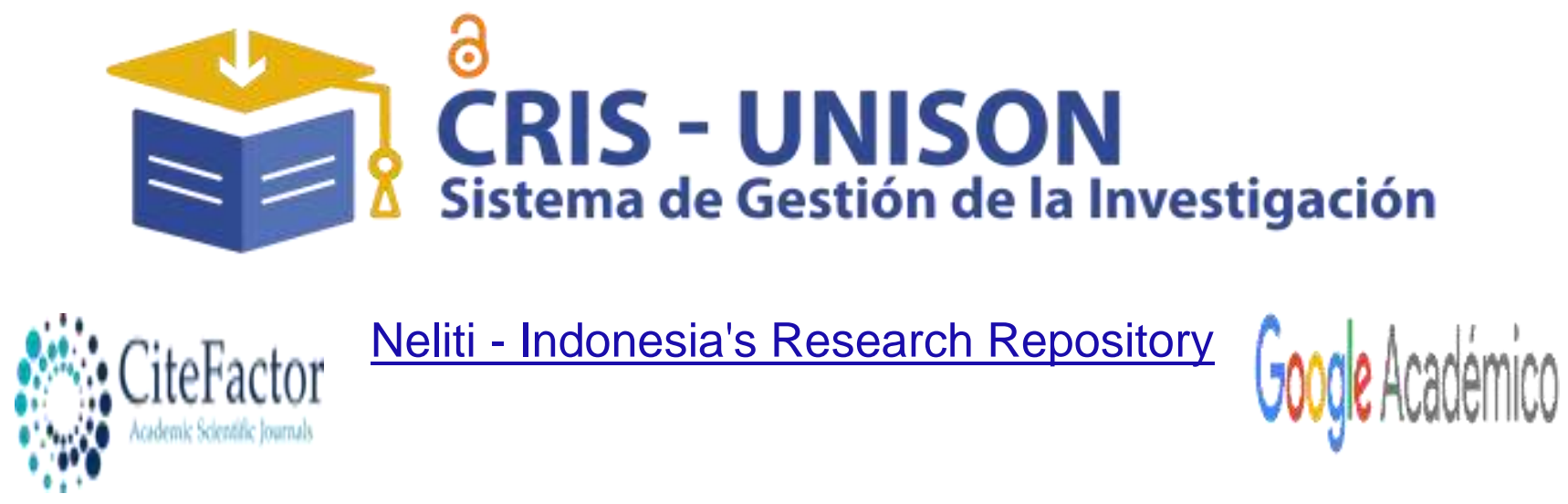

DDialnet

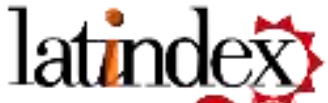

catálog@e 20

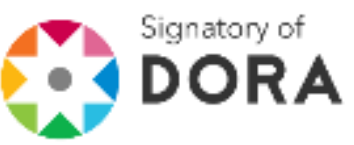

LatinREV

REDIB

Fied loencamaricane

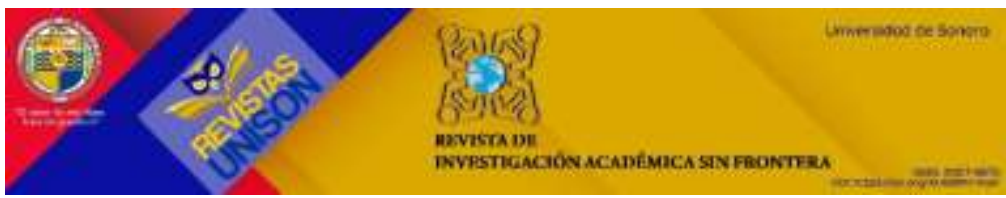

